\title{
Estado funcional e as políticas de ajuste estrutural na Educação Básica brasileira
}

\author{
Functional state and structural adjustment policies in \\ Brazilian Basic Education
}

\section{Situación funcional y politicas de ajuste estructural en la educación básica brasileña}

\author{
RENATA VALÉRIO SILVA (iDa \\ JaNi AlVeS dA Silva MoreIRA (iDb \\ MARIA EUNICE FRANÇA VolsI IDc
}

\section{Resumo}

O texto tem como objetivo analisar a concepção de Estado funcional e as políticas de ajuste estrutural para a educação básica no contexto de intensificação do neoliberalismo no Brasil. Se refere aos resultados de uma pesquisa exploratória de caráter bibliográfico e documental. Para dar conta do proposto, o texto analisa os pressupostos históricos e políticos do financiamento da educação básica e a questões históricas pertinentes, que desencadearam a intensificação das políticas de ajuste estrutural neoliberal na educação básica. Concluiu-se que as políticas de ajuste estrutural são resultados dos atos governamentais, que, por sua vez, caminham na contramão do que é condizente para os serviços públicos. As articulações entre o setor privado e público resultaram em políticas de ajustes estruturais que favorecem a economia e os interesses da elite brasileira e, nesse cenário, a educação básica pública é posta como uma mercadoria lucrativa. Isso, por sua vez, favorece a cultura de que o setor privado apresenta resultados, enquanto o setor público é visto como

\footnotetext{
a Universidade Estadual de Maringá (UEM), Maringá, PR, Brasil. Mestra em Educação, e-mail: rehvalerio@gmail.com

b Universidade Estadual de Maringá (UEM), Maringá, PR, Brasil. Doutora em Educação, e-mail: professorajani@hotmail.com

c Universidade Estadual de Maringá (UEM), Maringá, PR, Brasil. Doutora em Educação, e-mail: mefvolsi@uem.br
} 
ineficiente. É uma ótica de lógica mercadológica posta no sistema educacional como solução para os problemas enfrentados pela educação pública, que resulta na desvalorização do setor público.

Palavras-chave: Estado Funcional. Políticas de ajuste estrutural. Financiamento da Educação. Neoliberalismo. Educação Básica.

\begin{abstract}
The text aims to analyze the concept of functional state and structural adjustment policies for basic education in the context of intensification of neoliberalism in Brazil. It refers to the results of an exploratory research of bibliographic and documentary character. To give an account of the proposal, the text analyzes the historical and political assumptions of basic education financing and the pertinent historical issues, which triggered the intensification of neoliberal structural adjustment policies in basic education. It was concluded that the structural adjustment policies are the result of governmental actions, which, in turn, go against what is appropriate for public services. The articulations between the private and public sectors have resulted in structural adjustment policies that favor the economy and the interests of the Brazilian elite and, in this scenario, public basic education is seen as a lucrative commodity. Which, in turn, favors the culture that the private sector presents results, while the public sector is seen as inefficient. A perspective of market logic put in the educational system as a solution to the problems faced by public education, which results in the devaluation of the public sector.
\end{abstract}

Keywords: Functional State. Structural adjustment policies. Education Financing. Neoliberalism. Basic education.

\title{
Resumen
}

El texto tiene como objetivo analizar la concepción de Estado Funcional y las Políticas de Ajuste Estructural para la educación básica en el contexto de intensificación del neoliberalismo en Brasil. Se refiere a los resultados de una pesquisa exploratoria de carácter bibliográfico y documental. A la cuenta del propuesto, el texto analiza los presupuestos históricos y políticos del financiamiento de la educación básica y las cuestiones históricas pertinentes, que han desencadenado la intensificación de las políticas de ajuste estructural neoliberal en la educación básica. Es preciso señalar que las políticas de ajuste estructural son resultantes de los actos gubernamentales, que por su vez, caminan en contra la mano del que es concordante para las utilidades públicas. Las articulaciones entre o sector privado y el público resultaran en políticas de ajustes estructurales que favorecen la economía y los intereses de la elite Brasileña y, delante a este escenario, de hecho, la educación básica pública pone como una mercadoría lucrativa. Por consiguiente, favorece la cultura de que el sector privado presente resultados, mientras el sector público es visto como ineficiente. Una óptica de lógica 
mercadológica haya puesto en el sistema educacional como solución para los problemas enfrentados por la educación pública, que resulta en la devaluación del sector público.

Palabras clave: Estado Funcional. Políticas de Ajuste Estructural. Financiamiento da Educación. Neoliberalismo. Educación Básica.

\section{Introdução}

As políticas de financiamento da educação básica encontram-se em constante processo de mudança a cada gestão governamental no país. Por vezes, o enfrentamento faz-se na expressão descontínua do planejamento do governo, e em função disso são notórias as mudanças ocorridas no Estado e a disseminação das ideias neoliberais na educação; portanto, é preciso atentar-se ao seu contexto histórico e político para a compreensão do atual panorama social e sua repercussão na política para o financiamento e gestão da educação básica.

O presente texto tem como objetivo analisar a concepção de Estado funcional e as políticas de ajuste estrutural para a educação básica no contexto de intensificação do neoliberalismo no Brasil. A análise se concentra no período pós-2016, que teve como marco uma série de reformas para a Educação Básica, sob a condução e o processo de enfrentamentos e disputas com uma máquina estatal em sua governança corporativa versus pública.

O governo provisório de Michel Temer (2016-2018) no Brasil, em aliança com o empresariado brasileiro e o mercado internacional, posicionou-se a favor do mercado econômico, em detrimento dos serviços públicos e dos direitos humanos e sociais. Tal conjuntura teve a marca de conciliações em rede, em que a educação foi “[...] vítima de um grupo nacional, articulado ao desejo internacional, de mercado e de capital” (LASTÓRIA; SANTOS; MELLO, 2018, p. 40).

A proposta de estabelecer no Brasil um Estado funcional defendido pelo Partido do Movimento Democrático Brasileiro (PMDB), atualmente conhecido como Movimento Democrático Brasileiro (MDB) ${ }^{1}$, na cartilha Uma Ponte para o Futuro (2015),

\footnotetext{
${ }^{1}$ No ano de 2017, o então Partido do Movimento Democrático Brasileiro decidiu, após escândalos sobre corrupção envolvendo o ex-presidente Michel Temer (2016-2018), alterar a sua nomenclatura para Movimento Democrático Brasileiro (MDB), em que retoma a sua
} 
representou uma prévia do que estaria por vir, expondo as ideias e estratégias neoliberais que seriam implementadas no ano seguinte, o que resultou em políticas de ajustes estruturais, reconfigurando o sistema educacional no país e o seu financiamento.

O referencial teórico para a análise considera, sob uma perspectiva históricocrítica, a existência de um processo de construção e definição das políticas educacionais, a partir da influência de mecanismos de regulação. A regulação se refere aos processos de contaminação que, mediante Barroso (2003, p. 65), “[...] existe no nível da transferência dos conceitos, das políticas e das medidas postas em prática, entre os países, em escala mundial", como também por meio de empréstimos de políticas, modelos, discursos, práticas de outros sistemas educativos, cujos efeitos produzem convergência, normalização e externalização das políticas. Para dar conta da abrangência que circunda a problemática investigada, elencaram-se categorias analíticas a partir do método do Materialismo Histórico, no qual consideram-se a totalidade histórica, a contradição e a hegemonia como conceitos fundantes para a compreensão dos determinantes das particularidades do objeto investigado.

A partir da definição metodológica anunciada, em um primeiro momento, a análise compreende os pressupostos históricos e políticos do financiamento da Educação Básica, para em seguida examinar o conceito e o papel do Estado Funcional no contexto de intensificação do neoliberalismo, com recorte temporal a partir do pós-2016. Posteriormente, se compreendem as políticas de ajuste estrutural na educação básica sob o viés da ideologia neoliberal enquanto legitimadora do projeto do capital monopolista.

\section{Pressupostos históricos e políticos do financiamento da Educação Básica}

A história do financiamento da educação básica, no Brasil, tem uma longa trajetória de luta, permeada por conquistas e retrocessos. A Constituição da República dos Estados Unidos do Brasil, de 1934 (BRASIL, 1934), marca a vinculação

história de oposição feita durante o período da Ditadura Militar (1964-1985). O partido que tem o maior número de filiados e o maior número da bancada da Câmara dos Deputados é conhecido, agora, como MDB. 
constitucional de recursos destinados à educação, que permanece até o momento; todavia, como ressalva Pinto (2018), houve momentos de interrupções, como o período de Ditadura Militar (1964-1985). Nos últimos 40 anos, as políticas de financiamento para a educação pública sofreram alterações importantes, por exemplo, a EC n ${ }^{\circ}$ 14/1996 (BRASIL, 1996a), que criou o Fundo de Manutenção e Desenvolvimento do Ensino Fundamental e de Valorização do Magistério (Fundef), o qual foi substituído pelo Fundo de Manutenção e Desenvolvimento da Educação Básica e de Valorização dos Profissionais da Educação (Fundeb), no ano de 2006, por meio da EC n 53 (BRASIL, 2006), cujo término está previsto para o ano de 2020.

No que se refere à conquista da vinculação de impostos, a Constituição de 1934 foi a primeira Carta Magna a estabelecer vinculação constitucional de recursos para a educação pública no Brasil. No Art. 156, essa CF instituiu os percentuais de vinculação, sendo 10\% para União e municípios e 20\% para Estados e Distrito Federal. O Art. 157 da CF de 1934 “"...] é o precursor do que hoje se conhece como políticas de fundos, pois estabelece a criação de fundos especiais" (ARAÚJO, 2016, p. 95).

No ano de 1937, com a nova Constituição dos Estados Unidos do Brasil (BRASIL, 1937) houve um retrocesso na conquista em relação a Constituição de 1934, uma vez que a vinculação constitucional de recursos para a educação pública foi suprimida. Sendo assim, para o setor educacional, o contexto de 1937, com o Estado Novo e o período de golpe, foi marcado por retrocessos no financiamento da educação, os quais desencadearam um processo de desvalorização da educação pública.

A vinculação constitucional de recursos para a educação pública só retornou no ano de 1946, ano em que a Constituição dos Estados Unidos do Brasil (BRASIL, 1946), no Art. 169, estabeleceu que “Anualmente, a União aplicará nunca menos de dez por cento, e os Estados, o Distrito Federal e os Municípios nunca menos de vinte por cento" na educação (BRASIL, 1946). A CF de 1946 perdurou até o ano de 1967.

A Constituição Federal de 24 de janeiro de 1967 (BRASIL, 1967) foi a primeira Carta Magna que reconheceu a educação como um direito de todos e dever do Estado, texto que se encontra presente na atual Constituição da República Federativa do Brasil de 1988 (BRASIL, 1988). A organização de todo o sistema educacional estabelecida pela CF de 1988 distribuiu responsabilidades aos entes federados e determinou a 
porcentagem da vinculação de recursos para o financiamento da educação pública (ARAÚJO, 2016, p. 102-103).

Atualmente, a garantia de recursos para a educação também está ancorada no conceito de padrão mínimo de qualidade, presente na Constituição Federal de 1988, na Lei de Diretrizes e Bases para a Educação - Lei no 9.394/96 (BRASIL, 1996b), no Fundo de Manutenção e Desenvolvimento do Ensino Fundamental e de Valorização do Magistério (Fundef), Fundo de Manutenção e Desenvolvimento da Educação Básica e de Valorização dos Profissionais da Educação (Fundeb) e na Lei no 13.005, que aprovou o Plano Nacional de Educação (2014-2024) (BRASIL, 2014).

A educação é “[...] direito de todos, dever do Estado e da família” (BRASIL, 1988), logo, o Estado deve garantir uma educação pública de qualidade a todos. Assim, alguns elementos fundamentais encontram-se no "Art. 206. O ensino será ministrado com base nos seguintes princípios: [...] IV - gratuidade do ensino público em estabelecimentos oficiais; [...] VII - garantia de padrão de qualidade” (BRASIL, 1988).

O Estado torna-se imprescindível como agente propulsor e mantenedor da educação pública. Para tanto, a CF de 88 garante uma vinculação mínima de recursos financeiros arrecadados pelo governo, que devem ser aplicados na educação pública:

Art. 212. A União aplicará, anualmente, nunca menos de dezoito, e os Estados, o Distrito Federal e os Municípios vinte e cinco por cento, no mínimo, da receita resultante de impostos, compreendida a proveniente de transferências, na manutenção e desenvolvimento do ensino. [...] § $5^{\circ} \mathrm{A}$ educação básica pública terá como fonte adicional de financiamento a contribuição social do salário-educação, recolhida pelas empresas na forma da lei. (Redação dada pela Emenda Constitucional $n^{\circ} 53$, de 2006) (BRASIL, 1988).

Ao considerar a origem dos recursos destinados à educação, à luz do pressuposto de que todo cidadão contribui para a efetivação das políticas públicas, “[...] o governo de um país, União, Estado e município só pode administrar o território e fazer despesas porque tem uma receita2" (EDNIR; BASSI, 2009, p. 16). Essa receita advém dos tributos que todo cidadão paga, sendo que “[...] tributos, então, são valores que o governo cobra e que somos obrigados a pagar, pois deveriam financiar políticas públicas a nós destinadas” (EDNIR; BASSI, 2009, p. 17). Além disso, “[...] Os tributos

\footnotetext{
${ }^{2}$ Receita ou entrada; despesa ou saída (EDNIR; BASSI, 2009).
} 
também recebem diferentes nomes, de acordo com a forma como são recolhidos. Então, eles se dividem em três categorias: imposto, taxa e contribuição" (EDNIR; BASSI, 2009, p. 21).

Desse modo, os impostos que os cidadãos pagam financiam os serviços públicos. "Pode-se afirmar que o Brasil possui tripla vinculação de seus recursos públicos para a educação, sendo os impostos, salário-educação e percentual do PIB" (AMARAL, 2012, p. 20). Nesse sentido, os impostos são os tributos e o salárioeducação é uma contribuição social exigida das empresas e o percentual do Produto Interno Bruto (PIB) foi - e ainda é - uma luta constante.

O salário-educação, criado pela Lei no 4.440, de 27 de outubro de 1964 (BRASIL, 1964), constitui-se “[...] na segunda maior fonte de recursos para a educação" (MOREIRA, 2015, p. 148). Posto isto, o salário-educação é um adicional aos recursos destinados à educação "[...] calculado à base de 2,5\% sobre o total de remunerações pagas aos empregados segurados pelo INSS e se constitui em uma fonte de recursos das contribuições sociais” (MOREIRA, 2015, p. 148).

A atual Lei de Diretrizes e Bases da Educação Nacional (LDB) - Lei no 9.394/1996, ao reger a educação estabelece as despesas consideradas como Manutenção e Desenvolvimento do Ensino (MDE), bem como as despesas que não são consideradas MDE, “[...] ou seja, não é qualquer ação educacional que pode ser financiada com os recursos vinculados, mas aquelas que estão cobertas pela definição de MDE” (GOUVEIA, 2016, p. 79).

Os recursos destinados à MDE referem-se a uma questão de definição do que se pode gastar ou não, a partir do princípio de vinculação, no qual se deve definir o que é destinado como despesa de MDE. Pinto (2018a) salienta que a LDB nº 9.394/96 deixou brechas que podem inflar os gastos educacionais, como por exemplo a omissão de pagamento dos profissionais aposentados da educação, o que gera problemas na atualidade.

A política de fundos instituída a partir do Fundo de Manutenção e Desenvolvimento do Ensino Fundamental e de Valorização do Magistério (Fundef) e, posteriormente, com sua substituição, pelo Fundo de Manutenção e Desenvolvimento da Educação Básica e de Valorização dos Profissionais da Educação (Fundeb) foi uma conquista essencial para o campo educacional. O Fundef, 
instituído pela Emenda Constitucional no 14, de 12 de setembro de 1996b (BRASIL, 1996b), constituiu-se como um mecanismo contábil que estabeleceu a forma de redistribuir o dinheiro dentro de cada estado da federação, portanto não resultou em recursos novos (GOUVEIA, 2016).

O Fundef vigorou até o ano de 2006, e a proposta progrediu para o Fundo de Manutenção e Desenvolvimento da Educação Básica e de Valorização dos Profissionais da Educação (Fundeb), criado pela Emenda Constitucional no 53, de 19 de dezembro de 2006 (BRASIL, 2006), trata-se de um fundo especial, de natureza contábil, constituindo-se em vinte e sete fundos, no qual, também a título de complementação, há uma parcela de recursos federais, no âmbito de cada Estado, caso o valor por aluno não alcance o mínimo definido nacionalmente.

O Fundeb "É uma forma peculiar de concentrar e distribuir recursos destinados à Educação Básica” (CALLEGARI, 2013, p. 230), com vigência prevista até 31 de dezembro de 2020. A discussão acerca do Fundeb ancora-se em um fundo contábil que objetiva a redistribuição dos recursos. Moreira (2015, p. 145) afirma que o Fundeb “[...] representa uma proposta de racionalização dos gastos públicos ancorada na raiz quantitativa, ou seja, não é um critério pedagógico, mas sim contábil e que se expressa a velha ênfase" de que os recursos são suficientes, porém mal distribuídos, reafirmando a necessidade de uma gestão eficiente para a distribuição e utilização dos recursos pelas Unidades de Federação.

No ano de 2015, a Proposta de Emenda Constitucional (PEC) n 15 propôs tornar permanente o Fundeb. Essa Proposta está desde 03 de março de 2015 em discussão no Congresso Nacional. O intuito da PEC é elevar as discussões a respeito do Fundo para além do setor econômico e progredir para discussões de ordem social. A Proposta aborda questões como "planejamento e proibição de retrocessos" (SENA, 2015, p. 7). Além disso, “O grande mérito da proposta é tornar o Fundeb um mecanismo contínuo e estável, trazendo-o para o corpo permanente da Constituição" (SENA, 2015, p. 7).

As discussões acerca da proposta de tornar o Fundeb permanente continuam acirradas. A Confederação Nacional dos Trabalhadores em Educação (CNTE) publicou um documento intitulado "O Fundeb permanente e as duas principais propostas em discussão no Congresso Nacional" (2019), no qual afirma que a EC n ${ }^{\circ}$ 
53 de 2006 (BRASIL, 2006) aprimorou o compromisso da vinculação constitucional para o financiamento da educação básica pública. Além disso, o documento publicado pela CNTE alerta para a importância de revogar a EC no 95/2016 (BRASIL, 2016), visto que o país já sente o reflexo dessa Emenda, tendo em vista os contingenciamentos nas pesquisas realizadas pelo Ensino Superior e a ausência de compromisso em cumprir as metas estabelecidas no PNE, especificamente a Meta 20, a qual visa atingir 10\% do PIB para a educação. O documento elaborado pela CNTE enfatiza, ainda, que o período de crise fiscal que o país vivencia, bem como a criação da EC no 95/2016, encontra-se em consonância com o pensamento político que se instaurou no Brasil nas eleições de 2018 e com a intensificação do neoliberalismo, que se materializou nos cortes dos investimentos para a educação.

A fim de reverter essa situação de contingenciamentos para a educação, e cientes de que a não renovação do Fundeb trará maiores consequências para o financiamento da educação básica pública, os 27 governadores de estados brasileiros enviaram, no dia 7 de maio de 2019, a PEC nº 65 (BRASIL, 2019), por entenderem ser indispensável a permanência do Fundeb como forma de melhoria do atendimento escolar, para que seja atingido o padrão mínimo de qualidade no nível básico da educação. Sendo assim, a PEC n ${ }^{\circ}$ 65, de 2019, propõe tornar permanente o Fundeb e estabelecer:

[...] a necessidade de observância de metas de universalização da educação básica obrigatória e gratuita, de oferta gratuita da educação de jovens e adultos e de ampliação da oferta de educação infantil. Dispõe sobre o Custo Aluno-Qualidade Inicial e sobre o padrão mínimo de qualidade de ensino. Dispõe sobre a complementação de recursos do Fundo e sobre o piso salarial nacional para os profissionais da educação básica pública (BRASIL, 2019)³.

A discussão acerca das políticas de financiamento para a educação pública continua permeada de desafios e obstáculos e, para tentar superá-los, a PEC n ${ }^{\circ}$ 65/2019 propõe que a União aumente sua complementação de $10 \%$ para 40\% “ao final de 10 anos, partindo do patamar de $20 \%$ no primeiro ano de vigência do novo Fundo"; além disso, a PEC n 65 abarca novas fontes de recursos, como os resultantes da exploração de petróleo e gás natural, alegando que são fundamentais novas

\footnotetext{
${ }^{3}$ Até agosto de 2019, a PEC aguarda decisão do Congresso Nacional.
} 
configurações no financiamento para o cumprimento da Meta 20 do PNE (20142024) (CNTE, 2019) $)^{4}$

A busca por qualidade na educação, em prol da luta pela vinculação dos recursos financeiros para a educação, de modo que subsidiem de fato a qualidade almejada, enfrenta muitos obstáculos. Entre eles, destaca-se a Desvinculação de Receitas da União (DRU) criada no ano 2000. A DRU foi prorrogada por diversas vezes e, com a PEC nº 87/2015, a proposta é que ela se estenda até 2023 (BRASIL, 2015). Além disso, altera-se sua construção, pois:

A PEC aumenta de $20 \%$ para $30 \%$ a alíquota de desvinculação sobre a receita de contribuições sociais e econômicas, fundos constitucionais e compensações financeiras pela utilização de recursos hídricos para geração de energia elétrica e de outros recursos minerais (BRASIL, 2019, on-line).

A PEC no 87/2015 resultou na Emenda Constitucional n 93, de 2016 (BRASIL, 2016), que prorrogou a DRU até o ano de 2023, ampliando sua alíquota para 30\%. De acordo com Pinto (2018a, p. 853), essa porcentagem incide sobre as contribuições sociais e de intervenção no domínio econômico, “[...] mantendo-se a não aplicação de seus efeitos sobre a contribuição do salário-educação". O autor ressalta, ainda, que a EC n ${ }^{\circ}$ 93/2016 estabeleceu a desvinculação da “[...] receita de impostos, taxas e multas de estados, DF e municípios, com alíquota de 30\%, excluindo-se de seus efeitos as vinculações à educação e saúde” (PINTO, 2018a, p. 853).

O debate recorrente sobre os recursos destinados ao financiamento da educação estabelece 10\% do PIB como percentual a ser investido na educação, o que demonstra que deve existir um aumento gradativo de investimento nessa área. Conforme previsto na Meta 20, no Plano Nacional de Educação (2014-2024), esse percentual deve ser atingido até o final do decênio, visto que é considerada uma porcentagem ideal para a concretização da categoria padrão mínimo de qualidade,

\footnotetext{
4 "Atualmente (em 15/10/2019), existem quatro PECs sobre o FUNDEB permanente em tramitação no Congresso Nacional, estando uma na Câmara Federal e três no Senado. A da Câmara encontra-se em estágio mais avançado, embora a Comissão Especial, criada em 2015, para analisar a PEC ainda não tenha aprovado o substitutivo apresentado pela relatora Profa. Dorinha (DEM-TO). As do Senado (24/2017, 33/2019 e 65/2019) estão em início de tramitação, sendo que as duas primeiras se tornaram incongruentes diante dos avanços obtidos especialmente no texto da PEC 65/19 e parcialmente na PEC 15/15" (CNTE, 2019, p. 3).
} 
ampliando-se, assim, os recursos destinados para a educação em seus três entes federados. Todavia, cabe salientar que, em recente pronunciamento, o atual Ministro da Educação ${ }^{5}$ afirmou que se pretende rever esse índice e enfatizou que não é a favor de aumentar a vinculação de impostos para a educação (TOKARNIA, 2019).

\section{Estado funcional e a intensificação do neoliberalismo (pós-golpe 2016)}

Ao analisar os pressupostos históricos e políticos do financiamento da educação brasileira, considera-se que essa compreensão não pode ficar isolada da compreensão do Estado e do neoliberalismo, no processo de delineamento das políticas educacionais.

A história e a organização das sociedades são um movimento transitório que se altera e se transforma com o movimento das forças de produção, por intermédio das quais "Produzindo seus meios de vida, os homens produzem, indiretamente, sua própria vida material” (MARX; ENGELS, 1986, p. 27). É preciso produzir meios de vida para satisfazer as necessidades humanas, portanto "O primeiro fato histórico é, [...] a produção dos meios que permitem satisfazer essas necessidades" (MARX; ENGELS, 2008, p. 21).

O movimento da história dividiu a sociedade em classes, porém existe a dominação de uma classe sobre a outra, na qual "Os pensamentos da classe dominante são também em todas as épocas, os pensamentos dominantes; [...] expressão ideal das relações materiais dominantes; [...] expressão das relações que fazem de uma classe a classe dominante; em outras palavras, são as ideias de sua dominação" (MARX; ENGELS, 2008, p. 48).

\footnotetext{
${ }^{5} \mathrm{Na}$ época Abraham Weintraub (2019), que foi exonerado em 20 de junho de 2020 por meio do Decreto Presidencial publicado e retificado no Diário Oficial no dia 23 de junho de 2020 (DOI. Edição no 118, Seção 2, p.01).
} 
Nesse sentido, o neoliberalismo como doutrina ideológica surge no século $\mathrm{XX}^{6}$ a partir da retomada do ideário liberal e irrigado pelos valores de manutenção e acumulação do capital. Suas orientações e estratégias defendem o livre mercado sem intervenção do Estado, centram-se na privatização de empresas estatais e serviços públicos e na desregulamentação da economia por meio da diminuição da interferência dos poderes públicos sobre a iniciativa privada.

O neoliberalismo também apresenta alterações com o desenvolvimento histórico (VIANA, 2008) e, em meio ao período de crise estrutural e reestruturação produtiva do capital, sobretudo a partir da década de 1970 no contexto latino-americano, mudanças na configuração das políticas públicas foram ativadas por meio dos ajustes estruturais. No âmbito das políticas educacionais, os ajustes estruturais ocorreram mediante: a) Focalização: mecanismos de substituição da política de acesso universal pelo acesso seletivo mediante programas emergenciais e temporários à pobreza absoluta; b) Descentralização: não necessariamente desconcentrando o poder do Estado, mas sim a gestão dos grandes fundos; e c) Privatização: transferência de responsabilidades estatais, gestão dos serviços públicos para setores privados, o que demandou o crescimento da atuação do setor privado na educação pública (MORAES, 2001; MOREIRA, 2015).

No período em que se concentra a análise apresentada, a partir do pós-2016, a intensificação das medidas neoliberais no Brasil foi nítida, sobretudo a partir da atuação política e econômica guiada pelo plano de governo proposto pela gestão Temer (2016-2018). Em 29 de outubro de 2015, o Partido do Movimento Democrático Brasileiro (PMDB), atualmente Movimento Democrático Brasileiro (MDB), por meio da Fundação Ulysses Guimarães, publicou um documento contendo 19 páginas, intitulado Uma Ponte para o Futuro (2015), caracterizado como um "programa" que visava preservar a economia e seu desenvolvimento. O programa explanado recomendava as funções do Estado, a partir de uma concepção de "Estado

6 O neoliberalismo com suas nuances e perspectivas apresenta modelos teóricos e orientações políticas a partir de suas diferentes escolas. Moraes (2001) destaca três escolas do pensamento neoliberal, sendo: a) escola austríaca, liderada por Friedrich August Hayek, patrono do pensamento neoliberal contemporâneo; b) escola de Chicago, personificada por T. W. Schultz e Gari Backer, ligados à teoria do capital humano e, principalmente Milton Friedman; c) escola de Vírginia ou public choice, representada por Buchanan. 
Funcional"; portanto, esse seria mais um indício de intensificação do neoliberalismo que privilegia a classe dominante e minimiza as responsabilidades do Estado como gerador do Bem-Estar Social7.

Sendo o Estado aquele que promove as ações no campo da política, observou-se no plano governamental denominado Uma Ponte para o Futuro (PMDB, 2015) o pressuposto de que vigorariam ações golpeantes no âmbito dos serviços sociais e com ataques à classe trabalhadora, portanto foram tempos de muitos embates e resistências. As medidas postas em prática permanecem sendo efetivadas pelo atual governo ${ }^{8}$ de Bolsonaro (2019-até a presente data), com o mesmo propósito de abertura de mercado e privilégios para o setor privado, amplificando as mazelas no setor público e firmando compromissos alinhados aos ideais conservadores e de extrema direita.

As bases teóricas do conceito de Estado Funcional ancoram-se na concepção da governança pública versus corporativa, que é delineada pela lógica da Nova Gestão Pública (NGP), a qual se vincula ao modelo de Estado ultraliberal e que, no atual momento, passa por transição sob o ideário que segue tendências internacionais da administração pública, na era denominada por alguns como Pós-Nova Gestão Pública (Pós-NGP) (CAVALCANTE, 2018).

O ideário da pós-NGP tem sido pouco discutido ainda no Brasil. Estudos internacionais apontam que esse ideário se configura como uma "arma ideológica" que indica uma crise do modelo NGP e quer se colocar com uma nova proposta de governança modernista. As tendências da Pós-NGP estão marcadas por:

[...] colaboração e parcerias: processos colaborativos de variadas formas; redes: atuação em redes na provisão de serviços públicos; visão integrada e holística: serviços públicos integrados e perspectiva da administração como um todo - coesa e coerente; coordenação e controle: fortalecimento das capacidades de coordenação e monitoramento das políticas estratégicas, especialmente pelo núcleo de governo; accountability: processos de ampliação da prestação de contas e capacidade de

\footnotetext{
${ }^{7}$ Com relação ao conceito de Estado do Bem-Estar Social, no Brasil, a partir de Lessa (2013), pondera-se que há imprecisão do conceito e divergências entre autores. Para essa compreensão sugere-se a obra Capital e Estado de Bem-Estar: o caráter de classe das políticas públicas (LESSA, 2013).

${ }^{8}$ Cabe destacar a notícia na qual Temer proferiu que Bolsonaro tem dado continuidade ao seu governo, disponível em: https://exame.abril.com.br/brasil/temer-governo-bolsonarovai-bem-porque-esta-dando-sequencia-ao-meu/. Acesso em: 28 ago. 2019.
} 
respostas da administração pública à sociedade; participação e engajamento: ampliação de canais de participação social no policy-making e fomento ao envolvimento da sociedade; e-government: incorporação frequente do uso de tecnologias da informação para aumentar a transparência do setor público, bem como acesso e envolvimento do cidadão; liderança: importância do papel do líder (político, administrativo ou cidadão) na gestão pública, sobretudo em processos empreendedores; fortalecimento da burocracia pública: profissionalização e valorização do quadro funcional do Estado com vistas a torná-lo mais eficiente, interdisciplinar e responsivo à sociedade (CAVALCANTE, 2018, p. 20).

Trata-se de uma gestão voltada para o setor privado, com a intenção de incidir no setor público uma forma de administração privatista, para atender à demanda de políticos e empresários que discutem vagamente que os serviços públicos administrados pelo Governo Federal apresentam ineficiência. Dessa forma, a parceria entre público e privado é posta como um caminho para eliminar os coeficientes negativos dos serviços sociais.

O texto, publicado pelo então $\mathrm{PMDB}$, retratava o cenário de crise e intensificação neoliberal ao exigir a cooperação da população, uma forma de chamar a atenção dos cidadãos para o momento de crise do setor público, com o objetivo de ganhar a aprovação populista para inserir a atuação do setor privado no setor público, sem obstáculos.

O neoliberalismo tem como característica a apresentação de um diagnóstico caótico quanto aos setores econômico, político e social; em seguida, prega uma receita salvacionista, na qual recomenda reformas aligeiradas e descontínuas. O plano de governo do PMDB afirmava que a "Estagnação econômica e esgotamento da capacidade fiscal do Estado não são fenômenos circunscritos apenas à esfera econômica. São fontes de mal-estar social e de conflitos políticos profundos” (PMDB, 2015, p. 3), além de expor que, embora o Estado apresente-se grande quanto aos serviços prestados, não oferece oportunidades de aumento de renda para a maior parte da população. Com isso, justificam que as ações advindas do sistema econômico são fragmentadas e sem articulação com o setor social.

A partir dessa visão foram aprofundadas as políticas de ajustes estruturais neoliberais, em que o Estado é posto como ineficiente perante as suas responsabilidades. A presente análise corrobora que o Estado tem suas falhas enquanto gestor, mas ao favorecer o setor privado nega-se a realidade brasileira, diante 
da crescente desigualdade social. O princípio que rege essas ideias de mercantilização dos serviços sociais é o de que as pessoas devem pagar pelos serviços para que estes sejam valorizados (SOARES, 2003, p. 12).

Diante do cenário caótico de estagnação econômica, o neoliberalismo não demonstra ações pertinentes à realidade social brasileira, mas, sim, atuações que favorecem o mercado e aumentam as desigualdades sociais. E como prognóstico para minimizar a crise do setor econômico, ataca os setores da saúde e educação, alegando que "[...] é necessário em primeiro lugar acabar com as vinculações constitucionais estabelecidas" (PMDB, 2015, p. 9) para restaurar a economia. Não seria absurdo verificar condutas como essas sendo praticadas por governos neoliberais, pois, conforme expõe Freitas (2018), os neoliberais olham para a educação a partir de sua concepção de sociedade baseada em um livre mercado.

O desmantelamento dos setores sociais, tendo como foco o setor da educação, evidencia um jogo de interesses do governo para com o empresariado. A necessidade de atender às demandas dos detentores do capital resulta na decadência no cumprimento constitucional, no que concerne à garantia de serviços públicos de qualidade para a sociedade. Ao analisar a proposta do PMDB, fica nítida a defesa de que “[...] para o Brasil voltar a crescer economicamente, é necessário rever as vinculações constitucionais estabelecidas, como as despesas com educação e saúde" (MATTOS et al., 2016, p. 175). Nesse sentido, os autores explicam que:

O fim das vinculações implica em um Estado que reduz seu papel de provedor da educação pública, gratuita e de qualidade. O projeto está na contramão do Plano Nacional de Educação (PNE) 2014-2024 e esboça uma visão mercantil da economia, mais preocupada com a regulação do mercado do que com o bem-estar social da população (MATTOS et al., 2016, p. 175).

Assentado nos princípios neoliberais, o programa do PMDB defendeu:

[...] as discussões sobre o tamanho e o escopo do Estado quase sempre se movem no vazio, porque a questão central é que o Estado deve ser funcional, qualquer que seja o seu tamanho. Para ser funcional ele deve distribuir os incentivos corretos para a iniciativa privada e administrar de modo racional e equilibrado os conflitos distributivos que proliferam no interior de qualquer sociedade (PMDB, 2015, p. 4, grifos nossos). 
Conforme característica das ideias neoliberais, o texto propõe que sejam realizadas "reformas estruturais", alegando que "[...] a parte mais importante dos desequilíbrios é de natureza estrutural e está relacionada à forma como funciona o Estado brasileiro" (PMDB, 2015, p. 5). Com o intuito de preparar o campo para ações futuras, reitera também que “[...] Nos últimos anos é possível dizer que o Governo Federal cometeu excessos, seja criando novos programas, seja ampliando os antigos” (PMDB, 2015, p. 5), assim como aponta que a solução para essa crise instaurada no país é "[...] mudar leis e até mesmo normas constitucionais". Cabe salientar que os excessos cometidos pelos governos anteriores, mencionados no Programa do PMDB, enquadram-se evidentemente nos períodos de gestão do Partido dos Trabalhadores (PT), em que os investimentos na área social foram maiores.

Nessa conjuntura de mudanças, o golpe ocorrido na gestão de Dilma Rousseff (2011-2016) foi dado como constitucionalmente legal e as ações seguintes do governo Temer (2016-2018) foram o ápice do neoliberalismo. Como exemplo disso, tem-se a Emenda Constitucional no 95 de 2016, a qual “Altera o Ato das Disposições Constitucionais Transitórias, para instituir o Novo Regime Fiscal" (BRASIL, 2016, on-line). Em linhas gerais, a EC 95 congela os recursos destinados à saúde e à educação pelos próximos 20 anos, assunto que será abordado no decorrer desta pesquisa. Medidas como essas já se descortinavam em 2015, uma vez que o documento Uma Ponte para o Futuro (2015) já esboçava o cenário vindouro, tendo em conta a imposição do ponto de vista de que, para o Brasil voltar a ter um crescimento sustentável, seria:

[...] necessário um grande esforço legislativo porque as leis existentes são, em grande parte, incompatíveis com eles. Vamos precisar aprovar leis e emendas constitucionais que, preservando as conquistas autenticamente civilizatórias expressas em nossa ordem legal, [...] para corrigir suas disfuncionalidades e reordenar com mais justiça e racionalidade os termos dos conflitos distributivos arbitrados pelos processos legislativos e as ações dos governos. [...] Será uma grande virada institucional e a garantia da sustentabilidade fiscal, que afetarão positivamente as expectativas dos agentes econômicos, a inflação futura, o nível da taxa de juros e todas as demais variáveis relevantes para a estabilidade financeira e o crescimento econômico (PMDB, 2015, p. 16).

Ficou explícito que, para esses ajustes na economia se viabilizarem, o Estado deveria “[...] cooperar com o setor privado na abertura dos mercados externos" 
(PMDB, 2015, p. 17) e operar com uma política articulada com os objetivos mercantilistas, que compreendem a livre iniciativa e a livre competição. Diante do panorama neoliberal em prática, o Brasil entra em uma fase de descaso social, conservadorismo moral, desmantelamento da Educação e retrocessos incessantes.

A Nova Gestão Pública combina o gerencialismo, o governo empreendedor e a governança, buscando tornar a gestão pública mais eficaz e mais eficiente, visando a sua modernização e procurando "[...] corresponder às expectativas do mercado dentro da lógica das empresas privadas lucrativas" (CÓSSIO, 2018, p. 69). Além disso,

A reforma gerencial visa a adotar no setor público o modelo organizacional e de gestão utilizado pelas grandes corporações da iniciativa privada, ou seja, busca inserir na raiz do sistema público conceitos e práticas voltados a eficiência, eficácia, competitividade, administração por objetivos, meritocracia e demais concepções oriundas de um meio em que a finalidade é a obtenção de lucro e que, portanto, dispensa pouca atenção para as finalidades sociais (CÓSSIO, 2018, p. 68).

Vale destacar que, no caso brasileiro, a reforma do Estado materializa-se de forma objetiva em 1995, com o Plano Diretor da Reforma do Aparelho do Estado, produzido pelo Ministério da Administração e Reforma do Estado, sob a gestão do ministro Bresser Pereira, no primeiro mandato do presidente Fernando Henrique Cardoso. As estratégias assinaladas pelo plano são: privatização, publicização e terceirização (CÓSSIO, 2018, p. 69).

Combinação posta em prática e que, na atualidade, avança rapidamente sob o requentar de um "novo" modelo denominado como Pós-Nova Gestão Pública, uma gestão na qual a presença do setor privado nas ações do setor público é naturalizada e a influência privatista é implementada por meio de ajustes estruturais e reformas incessantes, com viés economicista, caráter privatista, mas propagado com caráter social, a fim de proporcionar melhores rendimentos à população.

Ainda diante desse cenário econômico, vislumbra-se uma era denominada por alguns sociólogos como crise da democracia. Castells (2018, p. 13) afirma que atualmente há uma crise de legitimidade política na democracia liberal, pois se assenta um rompimento no "[...] vínculo subjetivo entre o que os cidadãos pensam e querem e as ações daqueles a quem elegemos e pagamos". Produz-se, assim, o que se denomina como crise de legitimidade política, ou seja, um cenário político em que os 
atores representantes da política não mais representam os cidadãos. Como pondera Castells (2018):

A política se profissionaliza, e os políticos se tornam um grupo social que defende seus interesses comuns acima dos interesses daqueles que eles dizem representar: forma-se uma classe política que, com honrosas exceções, transcende ideologias e cuida de seu oligopólio (CASTELLS, 2018, p. 13).

Levitsky e Ziblat (2018) também discorrem sobre o processo de crise das democracias e afirmam que as democracias tradicionais do mundo estão vivenciando um processo de "recessão democrática" que, por vezes, decai aos poucos em processos não visíveis, nos quais “[...] autocratas eleitos mantêm um verniz da democracia enquanto corroem a sua essência" (LEVITSKY; ZIBLAT, 2018, p. 17-18), por meio de subversões, aparelhando tribunais e outras agências neutras e usando-os como arma, comprando a mídia e o setor privado, usando, assim, as instituições da democracia de forma gradual e sutil para exterminar a própria democracia.

\section{Políticas de ajuste estrutural da Educação Básica}

$\mathrm{Na}$ perspectiva neoliberal anunciada enquanto legitimadora do projeto do capital monopolista que rompe com as restrições que limitam a sua liberdade de movimento (NETTO; BRAZ, 2012), o Estado é exposto como um sistema ineficiente que deve ser reformado, assim as políticas de ajustes estruturais ganharam força, por se configurarem como "[...] parte de um movimento de ajuste global, que se desenvolve num contexto de globalização financeira e produtiva” (SOARES, 2003, p. 19).

As políticas de ajustes estruturais neoliberais são definidas em uma relação de cooperação internacional e expressam o retrocesso das conquistas do Estado de BemEstar Social, visto que, sob essa ótica de mercado, os neoliberais alegam que foram os gastos generosos dos Estados de Bem-Estar que causaram os déficits fiscais dos países que os adotaram (SOARES, 2003).

Essas políticas caracterizadas por cortes financeiros para os setores públicos configuram-se em 
[...] um conjunto, abrangente, de regras de condicionalidades aplicadas de forma cada vez mais padronizada aos diversos países e regiões do mundo, para obter apoio político e econômico dos governos centrais e dos organismos internacionais. Trata-se também de políticas macroeconômicas de estabilização acompanhadas de reformas estruturais liberalizantes (SOARES, 2003, p. 19).

Contrariamente ao ideal para os serviços públicos, essas reformas estruturais são "[...] centradas na desregulamentação dos mercados, na abertura comercial e financeira, na privatização do setor público e na redução do Estado" (SOARES, 2003, p. 19). Assim, as reformas estruturais assumem, além de uma natureza econômica, "[...] uma redefinição global do campo político-institucional e das relações sociais" (SOARES, 2003, p. 19).

Nesse cenário de intensificação do neoliberalismo, “[...] o objetivo real do capital monopolista não é a ‘diminuição' do Estado, mas a diminuição das funções estatais coesivas, precisamente aquelas que respondem à satisfação de direitos sociais" (NETTO; BRAZ, 2012, p. 239), como a Educação Básica.

Ante a esse panorama de retrocessos posto em um período pós-golpe, o “[...] ajuste neoliberal não é apenas de natureza econômica: faz parte de uma redefinição global do campo político-institucional e das relações sociais" (SOARES, 2009, p. 12). Instalou-se um espetáculo de reformas no serviço educacional, por vezes, a caracterizar-se como sem projeto e sem planejamento, estabelecendo insegurança e insatisfação para aqueles que acreditam em uma educação pública de qualidade para todos.

As reformas pautadas em políticas de ajustes estruturais visam desencadear as mudanças necessárias, por meio de políticas liberalizantes, privatizantes e de mercado. Em suma, propõe-se reduzir o gasto público, a fim de aumentar a aplicabilidade em liberar o mercado exterior e " [...] atenuar as regulações estatais maximizando o uso do mercado; concentrar o investimento no setor privado, comprimindo a presença do setor estatal" (SOARES, 2009, p. 15). E, nesse jogo de interesses entre governos elitistas e agentes do mercado exterior, os serviços públicos vão sendo deteriorados.

No período denominado de pós-golpe 2016, as reformas educacionais intensificaram-se por meio de ações e medidas do governo, tais como: a reforma do Ensino Médio iniciada pela medida provisória no 746/2016, materializada pela Lei nº $13.415 / 2017$; a criação de uma Base Nacional Comum Curricular (BNCC), aprovada em dezembro de 2017, para a educação infantil e ensino fundamental, e em 2018, para o ensino médio; e a 
Proposta de Emenda Constitucional (PEC) 241/55, que resultou na Emenda Constitucional (EC) no 95, o ápice das políticas de ajustes estruturais concretizado.

Esse processo de implementação e intensificação do ideário neoliberal tem sido resultado de reformas estruturais na educação, as quais estão

[...] centradas na desregulamentação dos mercados, na abertura comercial e financeira, na privatização do setor público e na redução do Estado - assumem uma convergência forçada nas medidas recomendadas pelo Banco Mundial, que ganham força de doutrina constituída, aceita por praticamente todos os países (SOARES, 2009, p. 16).

As reformas estruturais desqualificam os serviços públicos, caracterizando o Estado como ineficiente. Esse fenômeno demonstra que um "[...] traço comum nas estratégias neoliberais de (des)estruturação dos serviços sociais públicos é a descentralização de serviços sociais" (SOARES, 2009, p. 77). Esse "livre jogo do mercado" implica, como já foi mencionado, desregulamentar os serviços sociais e entregar essa responsabilidade do Estado para empresas privadas, uma vez que

Um dos componentes ideológicos por trás desse tipo de proposta é a ideia de que o setor público caracteriza-se, por princípio, em qualquer circunstância, como ineficiente e ineficaz, ao contrário do setor privado, o único a possuir uma "racionalidade" e uma "vocação" capazes de levar ao crescimento econômico. As possibilidades de sucesso da proposta privatizante estariam assim garantidas desde que o Estado não interferisse (SOARES, 2009, p. 40).

Essas políticas de ajustes estruturais resultam em ações do governo que caminham paralelas às orientações e recomendações de instituições financeiras, como o caso do Banco Mundial (BM). Os empréstimos concedidos pelo banco ao Brasil apresentam uma série de condicionalidades, que visam descentralizar o Estado e favorecer o empresariado. O BM atua na estrutura dos gastos públicos, no que é chamado, de acordo com Toussaint (2002), de exame revisto dos públicos, que tem por objetivo analisar o orçamento público do país e realocar seus recursos.

Nessa perspectiva, essas instituições financeiras internacionais, "No que diz respeito aos setores sociais [...] insistem no princípio da cobrança dos custos aos usuários [...] e na retirada gradual do Estado dos serviços básicos, da saúde e educação" (TOUSSAINT, 2002, p. 205). Essas medidas passam a ser acatadas por governos neoliberais com discursos referentes ao crescimento sustentável da 
economia, atacando os serviços sociais, vendo-os como os maiores vilões dos cofres públicos. A liberalização dos preços consiste em eliminar o controle sobre os preços, ao mesmo tempo em que promove a desvalorização dos produtos internos (TOUSSAINT, 2002).

As ações do BM, junto aos ideais neoliberais, propõem que os serviços ofertados pelo Estado se tornem cooperativos e cobrem uma taxa do indivíduo que pretende obter um serviço, ou ainda que o setor privado assuma os serviços fornecidos e faça sua livre competição. Essas questões do campo econômico atingem diretamente a educação, por tratar-se de um serviço público de responsabilidade do Estado.

O setor privado recomenda a retirada do Estado em ações do serviço público, tornando-o cada vez mais precário. O Banco Mundial (BM) apresenta as propostas ao país que necessita de empréstimo, impondo suas condições. O país, por sua vez, adere àquelas que "julga" ser necessário para o momento e que, em grande parte, favorecem o setor privado. Nesse sentido, a roupagem de "boa governança":

[...] não implica de nenhuma maneira democracia; implica a implementação de políticas que permitam obter consentimento dos oprimidos. Em numerosos casos, o discurso sobre a boa governança dissimula mal uma prática que visa a reforçar o Poder Executivo e a enfraquecer os movimentos sociais (TOUSSAINT, 2002, p. 214).

No contexto do Estado funcional, com bases ancoradas na Pós-NGP, as políticas de ajustes estruturais caminham pela mão do mercado internacional, combinando as privatizações do setor público e o desmantelamento das políticas sociais, em específico, as educacionais, por meio de contingenciamentos e reformas educacionais descontínuas. Esse período se refere à inauguração de uma fase denominada como Pós-NGP no Brasil, sendo assim, a crise do setor público recebeu um viés economicista, político e social.

\section{Considerações finais}

Ao analisar a influência da configuração do Estado e das políticas de ajustes estrutural na educação básica, cabe salientar que esse processo de influência representa a intensificação de medidas austeras neoliberais, que atendem aos interesses do mercado internacional. Mediante esse aspecto, há um constante 
enfrentamento entre os interesses do setor público e privado, que impedem o avanço da qualidade do ensino público, visto que não há empenho da atual política governamental no país em estabelecer um padrão mínimo de qualidade para a educação, a partir do cumprimento das estratégias e metas acordadas no atual Plano Nacional de Educação, Lei no 13.005/2014 (BRASIL, 2014).

As políticas de ajustes estruturais favorecem a economia e os interesses da elite brasileira e, nesse cenário, a educação pública é colocada sob a ótica de um produto mercantilista, o legado da educação pública é posto como insuficiente e incompetente por meio de dados e índices que se alcançam com as avaliações externas. As articulações e disputas de interesses provenientes de representantes técnicos e redes políticas dos setores privados e do mercado no processo de construção dessas políticas fazem com que a educação básica pública seja definida como um sistema falho, que não é capaz de atender as demandas sociais.

Essa disputa, embalada por um discurso convincente e ensejado por um quadro problemático e precarizado que se instala na educação pública, aumenta a dificuldade no enfrentamento dos inúmeros problemas que, maiormente, são consequências da falta de recursos e de uma gestão educacional adequada e contínua. Tal fenômeno favorece a complexidade de uma cultura que valoriza a atuação do setor privado como consistente e ideal, em detrimento de uma educação pública sob responsabilidade estatal.

As atuais reformas educacionais pós-2016 ressaltam nos enunciados políticos que o objetivo tem sido prover uma educação pública de qualidade, porém se abstêm desse intuito ao articular-se com o empresariado, visto que colaboram com a elevação do lucro para o setor privado e não com a construção de um sistema público de qualidade permanente, que atenda às necessidades de todos.

\section{Referências}

AMARAL, N. C. Para compreender o financiamento da educaşão básica no Brasil. Brasilia: Lỉber Livro, 2012. ARAÚJO, L. O CAQi e o novo papel da União no financiamento da Educação Básica. Jundiaí: Paco Editorial, 2016.

BRASIL. [Constituição (1934)]. Constituição da República dos Estados Unidos do Brasil de 1934. Brasília, DF: Presidência da República. Disponível em: 
http://www.planalto.gov.br/ccivil_03/Constituicao/Constituicao91.htm. Acesso em: 21 jul. 2020.

BRASIL. [Constituição (1937)]. Constituição dos Estados Unidos do Brasil de 1937. Brasília, DF: Presidência da República. Disponível em: http://www.planalto.gov.br/ccivil_03/Constituicao/Constituicao37.htm. Acesso em: 21 jul. 2020.

BRASIL. [Constituição (1946)]. Constituição dos Estados Unidos do Brasil de 1946. Brasília, DF: Presidência da República. Disponível em: http://www.planalto.gov.br/ccivil_03/constituicao/constituicao46.htm. Acesso em: 21 jul. 2020.

BRASIL. [Constituição (1967)]. Constituição da República Federativa do Brasil de 1967. Brasília, DF: Presidência da República. Disponível em: http://www.planalto.gov.br/ccivil_03/Constituicao/Constituicao67.htm. Acesso em: 21 jul. 2020.

BRASIL. [Constituição (1988)]. Constituição da República Federativa do Brasil de 1988. Brasília, DF: Presidência da República. Disponível em: http://www.planalto.gov.br/ccivil_03/constituicao/constituicao.htm. Acesso em: 21 jul. 2020.

BRASIL. Lei no 4.440 de 27 de outubro de 1964. Institui o Salário-Educação e dá outras providências. Brasilia, 1964. Disponível em: http://www.planalto.gov.br/ccivil_03/Leis/1950-1969/L4440.htm. Acesso em: 21 jul. 2020.

BRASIL. Emenda Constitucional no 14, de 12 de setembro de 1996. Modifica os arts. 34, 208, 211 e 212 da Constituição Federal e dá nova redação ao art. 60 do Ato das Disposições Constitucionais Transitórias. 1996a. Disponível em: http://www.planalto.gov.br/ccivil_03/constituicao/emendas/emc/emc14.htm. Acesso em: 21 jul. 2020.

BRASIL. Lei n ${ }^{\circ} 9.394$, de 20 de dezembro de 1996. Estabelece diretrizes e bases da educação. Lei de Diretrizes e Base da Educação Nacional. 1996b. Disponível em: http://www.planalto.gov.br/ccivil_03/leis/19394.htm. Acesso em: 21 jul. 2020.

BRASIL. Emenda Constitucional no 53 de 19 de dezembro de 2006. Dá nova redação aos Arts. $7^{\circ}, 23$, 30, 206, 208, 211 e 212 da Constituição Federal e ao art. 60 do Ato das Disposições Constitucionais Transitórias. Disponível em: http://www.planalto.gov.br/ccivil_03/constituicao/Emendas/Emc/emc53.htm. Acesso em: 21 jul. 2020.

BRASIL. Lei no 13.005, de 25 de junho de 2014. Aprova o Plano Nacional de Educação - PNE e dá outras providências. Disponível em: http://www.planalto.gov.br/ccivil_03/_ato20112014/2014/lei/113005.htm. Acesso em: 21 jul. 2020.

BRASIL. Emenda Constitucional no 93/2016. Altera o Ato das Disposições Constitucionais Transitórias para prorrogar a desvinculação de receitas da União e estabelecer a desvinculação de receitas dos Estados, Distrito Federal e Municípios. Disponível em: http://www.planalto.gov.br/ccivil_03/constituicao/Emendas/Emc/emc93.htm. Acesso em: 21 jul. 2020.

BRASIL. Emenda Constitucional $n^{\circ} 95$ de 15 de dezembro de 2016. Altera o Ato das Disposições Constitucionais Transitórias, para instituir o Novo Regime Fiscal, e dá outras providências. Brasília, 2016. Disponível em: 
http://www.planalto.gov.br/ccivil_03/constituicao/emendas/emc/emc95.htm. Acesso em: 21 jul. 2020.

BRASIL. Senado Federal. Proposta de Emenda Constitucional no 65 de 2019. Brasilia, 2019. Disponível em: http://www.planalto.gov.br/ccivil_03/constituicao/Emendas/Emc/emc65.htm. Acesso em: 21 jul. 2020.

BRASIL. Proposta de Emenda Constitucional n 87 de 2015. Prorroga a vigência da Desvinculação de Receitas da União (DRU). Brasília, 2015. Disponível em: http://www.planalto.gov.br/ccivil_03/constituicao/emendas/emc/emc87.htm. Acesso em: 21 jul. 2020.

BARROSO, J. Organização e Regulação dos Ensinos Básico e Secundário, em Portugal: Sentidos de uma Evolução. Educação e Sociedade, Campinas, v. 24, n. 82, p. 63-92, abr. 2003.

CALLEGARI, C. O FUNDEB e o financiamento da educação pública no estado de São Paulo. São Paulo: Aquariana, 2013.

CASTELLS, M. Ruptura: A crise da democracia liberal. Rio de Janeiro: Editora Zahar, 2018.

CAVALCANTE, P. Convergências entre governança e o Pós-Nova Gestão Pública. Boletim de Análise Político-Institucional, n. 19, 2018.

CONFEDERAÇÃO NACIONAL DOS TRABALHADORES EM EDUCAÇÃO (CNTE). O FUNDEB Permanente e as duas principais propostas em discussão no Congresso Nacional. 2019. Disponível em: https://www.cnte.org.br/images/stories/2019/2019_05_14_fundeb_permanente\%20maio_201 9.pdf. Acesso em: 25 jan. 2021.

CÓSSIO, M. F. A Nova Gestão Pública: alguns impactos nas políticas educacionais e na formação de professores. Porto Alegre. Revista Educação, v. 41, n. 1, p. 66-73, jan./abr. 2018.

EDNIR, M.; BASSI, M. Bicho de sete cabeças: para entender o financiamento da educação brasileira. São Paulo; Petrópolis: Ação Educativa, 2009.

FREITAS, L. C. de. A Reforma Empresarial da Educação: nova direita, velhas ideias. São Paulo: Expressão Popular, 2018.

GOUVEIA, A. B. O Financiamento da Educação no Brasil e o Desafio da Superação as Desigualdades. In: SOUZA, A. R.; GOUVEIA, A. B.; TAVARES, T. M. Políticas Educacionais: conceitos e debates. Curitiba: Appris, 2016. p. 75-94.

LASTÓRIA, A. C.; SANTOS, J. F. A.; MELLO, R. C. Considerações sobre os retrocessos nas políticas educacionais brasileiras durante o governo do presidente Michel Temer. Revista Pedagógica, Chapecó, v. 20, n. 43, p. 18-41, jan./abr. 2018.

LESSA. S. Capital e Estado de Bem-Estar: O Caráter de Classe das Políticas Públicas. São Paulo: Instituto Lukács, 2013.

LEVITSKY, S.; ZIBLATT, D. Como as democracias morrem. Rio de Janeiro: Zahar, 2018.

MARX, K.; ENGELS, F. A Ideologia Alemã. 5. ed. Trad. José Carlos Bruni e Marco Aurélio Nogueira. São Paulo: Hucitec, 1986. 
MARX, K.; ENGELS, F. A Ideologia Alemã. 3. ed. Trad. Luís Claudio de Castro e Costa. São Paulo: Martins Fontes, 2008.

MATTOS, R. S. et al. O futuro do pretérito na educação brasileira: declinações dos direitos sociais sob a égide de "Uma Ponte para o Futuro". Revista Brasileira de Sociologia do Direito, v. 3, n. 1, jan./abr. 2016.

MORAES, R. C. Neoliberalismo: de onde vem para onde vai? São Paulo: Senac, 2001.

MOREIRA, J. A. S. Políticas de Financiamento e Gestão da Educação Básica (1990-2010). Maringá: Eduem, 2015.

NETTTO, J. P.; BRAZ, M. Economia Política: uma introdução crítica. 8. ed. São Paulo: Cortez, 2012.

PINTO, J. M. R. O financiamento da educação na constituição federal de 1988: 30 anos de mobilização social. Educaşão e Sociedade, Campinas, v. 39, n. 145, p. 846-869, out./dez. 2018 a.

PARTIDO DO MOVIMENTO DEMOCRÁTICO BRASILEIRO (PMDB). Uma ponte para o futuro. PMDB: Brasília, 2015.

SENA, P. Nota Técnica: a PEC no 15/2015 e o novo FUNDEB. Brasília: Consultoria Legislativa, 2015.

SOARES, L. T. O Desastre Social. Rio de Janeiro: Record, 2003.

SOARES, L. T. Os custos sociais do ajuste neoliberal na América Latina. 3. ed. São Paulo: Editora Cortez, 2009.

TOKARNIA, M. MEC quer alterar meta de investimento de 10\% do PIB. 2019. Agência Brasil, Brasília, 11 jul. 2019. Disponível em: http://agenciabrasil.ebc.com.br/educacao/noticia/2019-07/mec-quer-alterar-meta-deinvestimento-de-10-do-pib Acesso em: 21 jul. 2020.

TOUSSAINT, E. A Bolsa ou a Vida. A dívida externa do Terceiro Mundo: as finanças contra os povos. São Paulo: Fundação Perseu Abramo, 2002.

VIANA, N. Breve História do Neoliberalismo. Revista Enfrentamento, n. 5, jul./dez. 2008. 